\title{
A difusão do conhecimento científico sobre meio ambiente nos livros didáticos de História ${ }^{1}$
}

Jozimar Paes de Almeida ${ }^{2}$

\section{RESUMO}

Este artigo é um estudo no campo da história ambiental e ensino de história e, seu propósito foi procurar compreender como o tema transversal meio ambiente foi apresentado nos livros didáticos de história.

Palavras-chaves: ensino de história, história ambiental, história da ciência.

0 presente artigo objetivou analisar através de um estudo crítico o processo de difusão do conhecimento científico na abordagem do tema transversal Meio Ambiente, nos livros didáticos de história do primeiro ciclo.

Destes livros selecionamos alguns dos aprovados pela comissão composta pelo Fundo Nacional de Desenvolvimento da Educação do governo federal dando ênfase àqueles com maior destaque de classificação, bem como os livros que tiveram uma maior disseminação nacional. Buscamos, assim cruzar estes dois critérios para selecionar a nossa fonte de pesquisa e nela estudarmos como estão sendo apresentados os conceitos de meio-ambiente, utilizando-nos da história ambiental para aprimorarmos a nossa pesquisa.

Definimos também o nosso recorte temporal e de fonte bibliográfica em torno do ano de 2002, tendo em vista tanto a política de implantação dos Parâmetros Curriculares Nacionais (PCNS, 1998), como a repercussão simbólica de ter completado uma década o Encontro da Organização das Nações Unidas para 0 Meio Ambiente e Desenvolvimento, ocorrido na cidade do Rio de Janeiro em 1992. Nossa expectativa visava perceber os desdobramentos deste Encontro, por intermédio das publicações didáticas, tendo em vista a magnitude e o teor do evento.

\footnotetext{
1 Pesquisa desenvolvida junto a PPG-UEL.

2 Doutor em História - Professor do Departamento de História - UEL.
} 
Nossa preocupação, portanto, envolve este cruzamento complexo de assuntos: a indústria cultural produtora de livros didáticos, como referência de disseminação científica; a política pública dos PCNs e, finalmente, a análise das obras nos aspectos da aplicação dos conceitos ambientais pela história, buscando contemplar entre as obras escolhidas pela comissão governamental, as melhores classificadas e as mais vendidas.

Assim, buscamos explanar o assunto na seguinte seqüência: no primeiro momento, apresentaremos o tema e seus problemas expondo o livro didático e sua inserção na sociedade. Em seguida comentaremos a política dos PCNs e a questão da abordagem da Transversalidade e a história ambiental bem como as possibilidades de sua contribuição no estudos das relações sociedade-natureza, por intermédio de suas estratégias teórico metodológicas utilizada para ingressarmos no último tópico, que expõe uma análise e comentários sobre os livros escolhidos.

\section{A disseminação do conhecimento científico}

A difusão do conhecimento científico realiza-se por intermédio de vários meios, livros especializados, revistas científicas, vídeo conferências, ensino à distância por intermédio de rádio, TV e congressos científicos. No entanto, esta abrangência atinge em maior número apenas a chamada comunidade científica. Apenas quando as informações tomam uma dimensão de ampliação massiva, é que outros meios a reproduzem de uma forma mais abrangente como a mídia: Jornais, Rádio, TV.

Além da mídia como meio de transmissão massivo de informação, temos um outro meio, que pressupõe uma atividade diferenciada e que se utiliza de um conhecimento científico e sistematizado abrangendo a população nacional em idade escolar que se vê obrigada por força da lei a freqüentar a escola. Esta instituição possui assim, um papel fundamental na formação do cidadão em nossa sociedade, seja a escola criticada (ILLICH, 1982) ou não, a mesma se alastra aos mais recônditos grotões e nas suas atividades o professor exerce um papel primordial.

0 exercício profissional do professor está fundamentado às condições que o mesmo teve em sua formação e que está construindo em seu dia-a-dia, para desempenhar sua função seja ela sócio-cultural, ou mesmo proveniente 
da estrutura administrativa do ensino que comporta programas e conteúdos definidos em nível de política governamental.

Em nossa pesquisa nos restringimos ao estudo do entrecruzamento da história com a ecologia, no tema transversal meio ambiente por intermédio dos livros didáticos de história. Consideramos, no entanto, para futuras pesquisas, a abertura possível de se estudar, por exemplo, como o professor de história realiza na prática, a aula propriamente dita, com a articulação meio ambientehistória vinculado às suas condições de trabalho, formação e dos alunos envolvidos na atividade.

Construiu-se em nossa sociedade, em um longo processo histórico, ao qual nos abstemos de analisá-lo mais atentamente, para não perdermos o nosso foco, a chamada indústria cultural do livro didático que produz de centenas a milhares de títulos de obras e, de milhares a milhões de exemplares de livros que atingem todo o território nacional por intermédio de alunos e professores, movimentando vultosas somas monetárias no mundo do mercado editorial, tornando-se uma arena de acirrado conflito competitivo entre as editoras.

Na década de 1990, grande parte da população em idade escolar, 86\%, está matriculada nas escolas (CAIMI, 2002, p. 41) demonstrando cabalmente a amplitude da disseminação do conhecimento escolar no território nacional. A revista Nova Escola, destaca que a Fundação de Apoio ao Estudante, distribuiu para 28 milhões de alunos, 100 milhões de exemplares a um custo de 110 milhões de dólares, chegando a gerar o comentário irônico de que a Fundação transformou-se em um órgão de Apoio às Editoras (NOVA HISTÓRIA, 1994, p. 24)!

0 livro didático tornou-se o produto mais vendido pelas editoras brasileiras, constituindo-se em $61 \%$ dos exemplares e, 55\% do faturamento no setor $^{3}$. Ana Tereza de Souza e Castro Purificação em sua dissertação de mestrado, (re)criando interpretações sobre a independência do Brasil: Um estudo das mediações entre memória e bistória nos livros didáticos (PURIFICAÇÃ0,2002), nos informa que o Ministério da Educação e Cultura, noticiou a quantidade distribuída de livros didáticos em todas as disciplinas para 0 ano de 2002, apresentando o recorde em disseminar 110,5 milhões de livros didáticos, sendo que os investimentos neles, de 1994 a 2001, alcançaram

3 Câmara Brasileira do Livro, Comportamento do Setor Editorial Brasileiro, 1996, p.2. 
a cifra de $\mathrm{R} \$ 2,4$ bilhões, beneficiando, em 2002, o total aproximadamente de 32 milhões de alunos em escolas públicas.

Com estes dados preliminares podemos constatar a magnitude da disseminação científica, bem como as bilionárias somas disputadas pelas empresas editoriais. No que diz respeito a este assunto, Miceli considera que podemos dizer que os livros didáticos têm servido muito mais aos interesses comerciais desta indústria, do que aos objetivos pretendidos pelos educadores (MICELI, 1996, p. 277).

0 mercado editorial no setor de livros didáticos, por conta desta intensa competição, realizou mudanças profundas nos aspectos da profissionalização da produção na década de 80 do século passado, exigindo uma divisão de trabalho de acordo com as funções dos profissionais envolvidos no processo produtivo: leitura crítica, edição e copidesque, revisão, edição de arte, diagramação e paginaç̧ão, ilustração, pesquisa iconográfica (FREITAS, 1998, p. 275). Circe Bittencourt reforça esta informação e, destaca "[....] que o livro didático como objeto da indústria cultural impõe uma forma de leitura organizada por profissionais e não exatamente pelo autor" (BITTENCOURT, 1997, p. 71).

0 livro também é visto:

Como objeto que difunde a palavra escrita, divulga idéias e mensagens através dos estímulos produzidos pela leitura de seus textos, o livro estimula o pensamento e enriquece o leitor espiritualmente, e o seu interior contém um saber racionalizado, organizado, veiculador de informações (ZAMBONI, 1996, p. 247).

Esse contexto histórico da produção do livro didático como uma valiosa mercadoria da chamada indústria cultural, detecta uma transformação profunda no seu processo produtivo, como antecipadamente comentamos e, neste momento, nos leva a traçar uma análise problematizadora sobre a sua importância, referente a sua própria constituição, isto é, seu conteúdo, como também no que diz respeito a sua utilização no ensino.

Fátima Araújo nos diz o seguinte:

0 livro didático é, por excelência, o instrumento essencial das aulas de História. É considerado, hoje, por muitos estudiosos como um dos problemas crônicos do 
ensino de 1 e 2 graus, haja vista ser ele o principal veiculador de conhecimentos sistematizado [...] (ARAÚJ0, 1999, p. 237).

Alguns dos problemas crônicos podem ser exemplificados quanto ao lugar de mediador principal que livro ocupa na relação professor/aluno, ao representar um conhecimento articulado que o aluno deve apreender e, além disso, também apresentar ao professor um plano linear e sequiencial de informações que devem ser ministradas. Assim, os encaminhamentos já estão previamente elaborados, basta, portanto, que professor e alunos sigam o direcionamento previamente traçado, implicando desta forma, na perda da autonomia das atividades de ensino/ aprendizagem dos sujeitos do processo educativo.

Este risco se amplia, pois o livro aparece como uma prática ao professor, excluindo uma crítica teórica metodológica do mesmo. Sendo utilizado, na maioria das vezes, como o principal recurso e fonte de consulta do professor e aluno, propícia uma divisão de conteúdo apropriado no que diz respeito a linguagem e das possibilidades de reflexão abstrata condizentes as diversas faixas etárias dos estudantes, apresentando um plano de ensino, as atividades extras e as possibilidades de utilização de diversas fontes: textos, músicas, mapas, quadro estatísticos, ilustrações (CAIMI e outros, 2002).

As editoras para poderem contemplar uma abertura de opções de escolha dos títulos, chegam a lançar até mais do que dois títulos por disciplina, em nosso caso, história, estes títulos se constituem em diferentes abordagens teóricometodológicas, por exemplo, circunscrevendo majoritariamente duas destas abordagens, uma apresentando modos de produção de influência marxista, e a outra decorrente da Escola dos Annales nesta última prevalece, uma interpretação da história cultural, apresentando propostas de estudo através de eixos temáticos (AVANCINI, 1998) .

Esta produção bibliográfica é atingida, tendo em vista, o disputado mercado editorial, por constantes reformulações, fazendo com que as obras estejam sendo diariamente re-atualizadas e revisadas, com inclusões de diferentes fontes ou de abordagens que a historiografia busca contemplar para atender as exigências de programas governamentais e/ou interesses dos professores.

Aos professores perante as suas condições de trabalho, formação e necessidade de intermitente pesquisa para a realização com qualidade de sua 
atividade profissional, não resta apenas a pretensa liberdade de escolha entre os variados títulos expostos nas prateleiras das livrarias, mas para além desta limitação, eles dispõem de possibilidades de intervenção direta na prática escolar utilizando criticamente os livros escolhidos e completando-os, com as suas interpretações e utilizando-se de outras fontes disponíveis que possam conseguir.

Desta forma, o professor pode demonstrar que o livro é fruto de uma produção e que ele, professor e os seus alunos, também têm possibilidades de produzirem as suas obras, isto é, tornarem-se autores. Esta atitude de autonomia e criação por parte do docente demonstra um risco para as empresas editoriais em nossa época da reprodutibilidade técnica, pois representa condições de se ampliarem autonomamente as perspectivas de produção, análise e reprodução do conhecimento histórico! A compreensão plural, dinâmica e complexa do mundo vem a tona como práxis.

No entanto, quando o livro didático se constitui na única fonte de consulta, seja do aluno, ou do professor, pode-se conduzir a um entendimento único da história, tendo em vista, inclusive, que pode se passar despercebido o entendimento do livro como o resultado de um conhecimento produzido por autores circunscritos a diferentes aspectos sócio-culturais, teórico-metodológicos, político-econômicos.

Entendemos que a utilização do mesmo, se fez dominante na relação professor/aluno, tanto pelas questões facilitadoras, mais também preocupantes, expostas no parágrafo anterior, quanto pelas condições de trabalho dos docentes que devido aos parcos salários têm que realizar uma carga horária excessiva, não dispondo de tempo e recursos econômicos para preparação de aulas, que envolve necessariamente uma pesquisa e acesso as várias fontes de informação.

Compreendemos assim, que o livro não é neutro, instrumento da verdade, "[ele] é um importante veículo portador de um sistema de valores, de uma ideologia, de uma cultura"(BITTENCOURT, 1997, p. 73). Por se configurar como uma das mais valiosas mercadorias da indústria cultural; pela sua amplitude de disseminação do conhecimento científico junto a população escolar, cabendo ao mesmo o papel de transposição das pesquisas avançadas, realizadas em laboratórios, institutos e centros de pesquisa; por intermédio de uma linguagem que busca se adequar as faixas etárias das crianças, por apresentar um desdobramento seqüencial do conteúdo disciplinar; por ser produzido por uma equipe técnica especializada em uma racionalidade 
produtiva empresarial, o livro carrega em si, valores, ideologia, e é sobre isso que nos alerta Chauí:

A lógica ideológica só pode manter-se pela ocultação de sua gênese, isto é, a divisão social das classes, pois sendo a "missão" da ideologia dissimular a existência dessa divisão, uma ideologia que revelasse sua própria origem se auto-destruiria. [...]. Trata-se, pois, da produção de uma gênese imaginária sustentada por determinadas "teorias" da história nas quais idéias, como as de progresso ou desenvolvimento têm a finalidade de colocar o presente como fase necessária do desdobrar do passado e do advento do futuro, estabelecendo continuidade entre eles. Assim, por exemplo, nos primórdios da ideologia burguesa, a gênese da sociedade era explicada por um pacto social como um "progresso" humano em face da Natureza, enquanto na ideologia burguesa contemporânea, a origem e a finalidade da sociedade são dadas pelas idéias de racionalidade, organização e planificação entendidas como um "progresso" no conhecimento "objetivo" das relações sociais (CHAUÍ, 1980, p. 25-26).

Esta análise contribui, não somente para o desvendamento do problema do livro, como também nos antecipa as idéias de progresso e desenvolvimento humano em relação a natureza que se expressam em obras didáticas, as quais comentaremos com mais detalhes posteriormente.

\section{Os PCNs, o meio ambiente e a história ambiental}

0 Ministério da Educação e Cultura, em 1994, convocou uma equipe de professores de escolas e de representantes da Espanha, Colômbia, Argentina, Bolívia e Chile, para sugerirem propostas que pudessem estabelecer Parâmetros Curriculares Nacionais. Em 1998, o MEC e a Secretaria de Educação Fundamental irão publicar a versão final destes parâmetros (MARTINEZ, 2003, p. 14).

A Associação Nacional dos Professores de História questionou a maneira pela qual os parâmetros foram elaborados e encaminhados para discussão nacional, considerando um erro a responsabilidade de resolução dos problemas nacionais que fora atribuída aos profissionais da educação (ARAS, 1999, p.384).

0 processo de reformas na educação amparadas na nova Lei de Diretrizes e Bases, dos PCNs e, das Diretrizes Curriculares Nacionais constituem-se na 
busca de um novo modelo de educação guiado pelos princípios do neoliberalismo que se consolida na competitividade e visa a rentabilidade. A escola pública teria o papel, segundo esses fundamentos, de ocultar a lógica capitalista, omitir o papel do Estado e de culpar o indivíduo quando este não fosse capaz de competir no mercado (MARTINEZ, 2003, p.23-24).

Joana Neves, ao tratar da inserção da disciplina história nos PCNs, nos alerta para duas questões, que precisariam ser melhor explicitadas, entre elas, por conta de nossa preocupação principal, escolhemos àquela que diz respeito aos temas transversais.

[...] os chamados Temas Transversais que, na forma como são apresentados, podem vir a provocar esvaziamento de conteúdos específicos, com a correspondente substituição dos mesmos por "conclamações" ("defender a natureza", "obedecer as regras de trânsito", "participar de campanhas comunitárias", "aceitar as diferenças culturais") eivadas de moralismo e carregadas de doutrinação (NEVES, 1999, p. 713).

A autora lembra-nos também, neste mesmo artigo, que a extensa dimensão dos PCNs, 6 textos, perfazendo 519 páginas em papel ofício, torna extremamente difícil aos professores, por conta das suas condições de trabalho, de realizarem uma leitura, análise, debate e de elaborarem propostas de modificação. Assim, quando convocados pelas instituições oficiais ou entidades, participam muito mais como ouvintes dos autores dos textos em questão.

Ulisses Araújo comenta sobre as seguintes dificuldades de implantação destas novas diretrizes curriculares:

[...] a grande maioria dos cursos de licenciatura e dos professores que por eles já passaram não refletem sobre o significado dessas novas diretrizes curriculares e respondem mecanicamente às exigências governamentais para a sua implantação, sem questionarem o que fazem e, por que o fazem (ARAUJ0, 1999, p. 35).

Esta ausência de preparação na análise e debate das diretrizes, no processo contínuo de formação docente repercute em sua atividade profissional, inclusive porque não tem ocorrido uma perspectiva de abordagem da transversalidade (GAVIDIA, 2002, p. 24) com respeito ao meio ambiente nos cursos de 
licenciatura na área de história. Entendemos por transversalidade a capacidade de se transpassar disciplinas que compõe o currículo escolar tradicional, por intermédio, por exemplo, de nosso tema em questão.

Quanto às perspectivas da realização da abordagem ambiental em nossos cursos de formação do professor de história, podemos considerar que há louváveis exceções em poucas universidades, mas raramente este campo temático, história ambiental, é ofertado como disciplina de caráter regular, no entanto, podemos dizer que este processo de se instalar tal vertente como área de pesquisa e de ensino vem progressivamente se consolidando, decorrente de trabalhos desenvolvidos por profissionais do meio acadêmico.

Buscar compreender a necessária articulação entre os campos do conhecimento científico, contribui para que possamos realizar esta reflexão. Notamos que os debates científicos que atualmente estão perpassando as universidades no mundo, apresentam um rico manancial de informações acerca dos desdobramentos do conhecimento nos mais variados campos e principalmente nas áreas das ciências exatas, biológicas e humanas.

Consolidou-se no campo da física por Einstein, Plank, Heisenberg, Bohr a chamada mecânica quântica, trazendo como contribuição o princípio da indeterminação, abalando os pilares do determinismo científico do século XIX.

Determinismo este que teve o seu engendramento inicial no século XVI em 1543, na revolução copernicana, que tirou o mundo da sua representação de órbita ptolomáica (geocêntrica). Os estudos foram apresentados como hipotéticos por Nicolau Copérnico em sua obra "De Revolutionibus Orbium Coelestium Libri", foram depois referendados por Johanes Kepler que formulou leis empíricas do movimento planetário através do estudo de tabelas astronômicas e, enfim, consolidados por Galileu.

Com Francis Bacon em sua obra "Novum Organum", apresenta-se o objetivo da ciência como um conhecimento que pode ser usado para dominar e controlar a natureza. Ele foi chanceler de Jaime I e acompanhou os processos inquisitórios do julgamento de bruxas, em que se utilizavam da tortura como um instrumento para extrair delas a "verdade". Busca assim utilizar-se do mesmo método na Natureza, enquanto "fêmea", para extrair dela as suas leis.

Descartes postulou a crença na certeza do conhecimento científico, considerando o universo material como uma máquina, portanto possuía leis 
mecânicas: tudo no mundo poderia ser explicado em função da organização e do movimento de suas partes. 0 seu método analítico de decompor problemas em partes componentes e dispô-las em ordem lógica criou a estrutura conceitual do pensamento científico moderno.

A formulação da concepção mecanicista da natureza teve o seu desenvolvimento com Isaac Newton, estabelecendo leis gerais do movimento que governam todos os objetos no sistema solar, das pedras aos planetas. 0 movimento da matéria ocorre pela atração mútua, a gravidade. Com suas teses constituíram-se a ciência e a tecnologia pesada.

A concepção do universo como um sistema mecânico composto de unidades materiais elementares; a concepção da sociedade como uma luta competitiva pela existência e a crença do progresso material ilimitado, a ser alcançado através do crescimento econômico e tecnológico, buscou tornar-se, enquanto método científico, na única abordagem válida do conhecimento.

Uma mudança nesta concepção começou a ocorrer com Michael Faraday e James Clerk-Maxweel. Eles estudaram os fenômenos eletromagnéticos descobrindo a atuação de um campo de força, e que nele existe a sua própria realidade não podendo ser estudados sem qualquer referência a corpos materiais. A luz é um campo eletromagnético.

A abordagem sobre os campos eletromagnéticos será aprofundada com os estudos de Einstein, considerando-os entidades físicas independentes que podem viajar através do espaço vazio e não podem ser explicados mecanicamente. Com a impossibilidade desta explicação mecânica Heisenberg apresentou o princípio da Indeterminação na qual o átomo sofria de uma crise de identidade: a impossibilidade de se medir simultaneamente o movimento e a posição de um elétron.

Veja-se por exemplo, como o físico teórico Fritjof Capra ilustra esta circunstância:

Os átomos consistem em partículas, e estas partículas não são feitas de qualquer substância material. Quando as observamos nunca vemos qualquer substância, o que vemos são modelos dinâmicos que se convergem continuamente nos outros - a continua dança da energia (CAPRA, 1987). 
Portanto, o conhecimento científico contemporâneo apresenta-nos um dado esclarecedor sobre o problema da indeterminação e ao utilizarmos do campo da física, podemos destacar ainda um outro componente conceitual importante para a nossa área de história ambiental: trata-se da questão da energia e o seu dispêndio que ocorre de uma forma intensa e deliberada pela produção humana. Estamos falando sobre a termodinâmica e, mais precisamente, da sua segunda lei, concebida intelectualmente por Sadi Carnot:a energia dissipada em calor não pode ser recuperada, e isto significa a conversão de energia mecânica em térmica.

Rudolf Clausius, no mesmo campo teórico, elabora o conceito entropia, utilizado para apresentar a medida de desordem em um sistema, significando desta forma, que existe uma dissipação energética sob a forma de calor. Assim, podemos constatar que com a ampliação e intensificação da utilização da energia mecânica que ocorre a partir da revolução industrial, aceleramos 0 processo de desordem térmica.

Podemos considerar que devemos no mínimo relativizar os processos de industrialização, no que diz respeito à centralização da produção, da utilização da energia, das grandes somas de capital, da exaustão dos recursos nãorenováveis e da degradação humana e do meio ambiente, com a poluição e o ritmo mecânico de produção imposto nas indústrias e nas agroindústrias (PAES DE ALMEIDA, 1998), assim como, a urbanização.

Entendemos que Enzo Tiezzi, contribui para esclarecer nosso assunto ao expressar que: " 0 tempo tecnológicoé inversamente proporcional ao tempo entrópico; o tempo econômico é inversamente proporcional ao tempo biológico" (TIEZZI, 1998, p. 32).

Buscar refletir historicamente, pela ótica da história ambiental, ao nosso ver, implica em detectar estes dilemas levantados no processo de criação/destruição ininterrupta da sociedade e da natureza.

Nas ciências humanas Edgar Morin pretende romper o pensamento dicotômico do Caos e do Cosmos, buscando compreender o Universo através de uma relação complexa, baseada no seu famoso tetragrama: ordem/desordem/ interação/organização. (MORIN, 1987)

Consideramos que a história seja um campo do conhecimento humano o qual por suas características, permite realizar reflexões que considerem o 
entrecruzamento das ciências. A ecologia possui também as mesmas características, afinal a poluição é um dos exemplos de que a produção humana ultrapassa fronteiras nacionais, de classe e gênero.

Resultado de uma compreensão mecanicista de mundo, buscava-se nas ciências biológicas uma ordenação do mundo biótico, quanto a este aspecto, vejamos como se procedeu o surgimento da ecologia como disciplina oriunda da biologia e criada por Ernest Haeckel em 1866. Este afimava que a ecologia é campo de conhecimento fundamentado no funcionamento das relações estabelecidas entre as espécies bióticas e abióticas formadoras de um ecossistema:

[...] um complexo relacionamento desordenado, interativo, dinâmico e constante de energia e matéria nos meios físico, biológico e social, possuindo uma capacidade auto-organizativa e reprodutiva que permite a geração e manutenção da vida. [...] Os elementos naturais que integram e formam esse complexo são constantemente reaproveitados em ciclos vitais, gerando um equilibrio auto-regulado, inclusive quanto a temperatura (homeostase), pela ampla diversidade de elementos e pela interdependência entre eles. [...] Em um ambiente fechado quando há rupturas em seu movimento, surge o perigo evidente de destruição do mesmo. Nesse sentido, o homem esuas atividades, ambos determinados historicamente e imersos no meio ambiente, podem contribuir para aumentar as probabilidades deste evento ao explorá-lo a uma velocidade ou intensidade que quebre a sua estabilidade. (...) É através do maior número possível de interligações quimio-fisio-biológicas provedoras do fluxo de energia e matéria no ecossistema, que se apresentam as condições de permitir a continuidade do ciclo da vida. Uma interação entre todos os elementos que compõem o planeta e mais a distância, a intensidade e incidência de raios solares e cósmicos, constituíram, por acaso, há bilhões de anos as condições de existência dos primeiros seres vivos que, multiplicando-se e estabelecendo relações desordenadas entre si, ocuparam a Terra. É por isso que a natureza não deve ser entendida como sinônimo de ordem e de sentido obrigatório (PAES DE ALMEIDA, 1996, p. 28-29).

A dinâmica da complexidade interativa deste sistema demonstra-nos o princípio de relacionamento integral de todos os elementos que o compõe. Entretanto, em determinadas pesquisas existe uma ênfase ora mais profunda 
dos aspectos naturais, funcionamento da natureza ora dos aspectos sociais, atuação das sociedades humanas com a natureza.

No decorrer do século XX, esta disciplina científica ampliou o seu campo de influência não se restringindo mais apenas ao campo das ciências naturais e atingiu também as ciências sociais. Como o ecossistema abrange o mundo natural, e o homem dele faz parte, pode-se inferir que neste processo dinâmico o ecossistema é uma relação social, pois está intrinsecamente integrado às ações humanas.

Assim, entendemos que os homens vivem em sociedade e organizam-se de diferentes formas para produzir a sua subsistência, retirada de uma fonte: a natureza. Nela repousam os elementos primordiais para a existência humana e de todos os seres vivos, pois ela é vida.

A noção de apropriação da natureza implica numa manipulação da mesma, subordinada aos fins propostos por seu dominador, que, em primeira instância, é o homem. Mas a atividade definidora e determinadora de tal apropriação está diretamente ligada à organização de sua produção econômicosocial e representada por expressões de valores culturais.

A natureza é vida, sendo realizada por um complexo sistema de condições atmosféricas, hidrológicas, geológicas, climáticas, energéticas, gerando ciclos bio-fisio-químicos favoráveis à composição de organismos vivos e que, por sua mortalidade, necessariamente têm que renovar-se constantemente, dependendo, pois, de seu bom funcionamento para que isto ocorra. Desta forma, as ações que a organização social efetuar sobre ela são de vital importância para a existência e condições de vida desta geração e conseqüentemente das futuras, sendo por este veio o caminho que escolhemos para realizar o nosso estudo.

\section{Livros didáticos e a história ambiental}

Arthur Sofiatti nos advertia em 1988, sobre a ausência da natureza nos livros didáticos de história, considerando como um dos fatores desta condição, refletidos também numa ausência de produção acadêmica, se devia ao caráter excessivamente antropocêntrico e sociocêntrico dos sistemas filosóficos ocidentais. Com relação às articulações sociedades humanas-natureza 0 autor identificou quatro vertentes de estudo: 
1. As transformações orgânicas que se operaram nos hominídeos, [...].2. As adaptações culturais ao ambiente natural. 3. A apropriação e a conseqüente modelagem do espaço-físico pelas sociedades humanas; e, finalmente, 4. As diferentes percepções de natureza pelos sistemas sócio-culturais. (SOFFIATI, 1988, p. 535)

Sugere ainda, a inclusão de tópicos sobre o meio ambiente nos livros didáticos e de suas respectivas representações mentais, bem como o alargamento de fontes e documentos para o trabalho com o tema.

Circe Bittencourt retoma esta preocupação em 2003, reconhecendo que ainda há entre os historiadores um "estranhamento" em relação à temática, como se os mesmos estivessem entendendo que estão invadindo um território alheio ou, como se a temática fosse exclusividade das áreas de biologia e/ou geografia.

No entanto, neste momento mais recente, reconhecemos uma incipiente produção acadêmica voltada para o tema, alertando para a possibilidade deste estudo se realizar por intermédio da interdisciplinaridade, das relações entre as esferas locais e globais e das ligações patrimônio cultural-meio ambiente. Apresenta-nos, também, um saudável desafio referente à produção de métodos para se trabalhar com esta temática (BITTENCOURT, 2003).

A partir destas considerações selecionamos nossos livros didáticos tendo como referência a década posterior ao encontro da $\mathrm{ONU}$, o pleno vigor dos PCNs, e buscando nos amparar num cruzamento articulado entre índice de vendagem de obras (SÁMOTTA, 2002, p. 210) e classificação das mesmas pela comissão do MEC. Chegamos as seguintes obras:

História e Vida Integrada, de Claudino Piletti e Nelson Piletti produzida pela editora Ática, com a maior classificação da comissão e com o maior índice percentual médio de vendas da 5 a 8 série $36,10 \%$, perfazendo em números absolutos de venda o total de 4.311.120 exemplares.

História Temática, de Andréa Rodrigues Dias Montellato, Conceição Aparecida Cabrini, Roberto Castelli Júnior, produzida pela editora Scipione, com a segunda classificação da comissão e, com o terceiro maior índice percentual médio de vendas da 5 a 8 série $8,52 \%$, perfazendo em números absolutos de venda o total de 1.014,204 exemplares.

Por fim, optamos pela obra, Trabalho e Civilização: Uma História 
Global, de Ricardo Maranhão e Maria Fernanda Antunes, editado pela Moderna, que foi classificada pela comissão e ficou com um número absoluto médio de vendagem 217.062 exemplares, buscamos assim, contemplar classificação oficial, vendagem e performance média.

Cada obra escolhida compõe-se de quatro volumes e para atingir as respectivas séries de 5 a 8 , visamos em nosso trabalho detectar quando e, de que forma o tema em questão se apresentava, com o intuito de buscar contribuir com a nossa análise no estabelecimento de sugestões indicativas de abordagem temática para o professor que tenha adotado a obra. Consideramos portanto, a estratégia da apresentação de perspectivas no sentido de ampliarmos o leque de possibilidades da práxis docente. No entanto, tendo em vista a dimensão das obras, optaremos por algumas passagens das mesmas com o objetivo de exemplificar a abordagem pretendida. Não se trata portanto, de se re-escrever todas as obras segundo a nossa perspectiva, mas de elaborar uma perspectiva teórico-metodológica que possa auxiliar o professor que utiliza-se do livro didático a problematizar a transversalidade sociedade-ambiente.

Vejamos inicialmente na obra de Ricardo Maranhão e Maria Fernanda Antunes a abordagem da história pela ótica do trabalho e, a possibilidade de relacioná-la com o tema ambiental:

[mineração na hispano-américa] Para explorar essas minas, além do trabalho indígena, introduziram-se melhorias técnicas como instrumentos de ferro, explosivos de pólvora e acima de tudo o uso de mercúrio, que permitia produzir uma prata mais pura (MARANHÃO e ANTUNES, 1999, p. 198).

Este parágrafo, por exemplo, nos permite a possibilidade de explorá-lo sob a ótica de história ambiental por intermédio de um levantamento de vários problemas decorrentes deste processo de extração mineral, temos então, a condição de estabelecer a relação direta do uso do mercúrio para purificar a prata, com a poluição dos rios e do seu ecossistema, gerando em decorrência problemas de saúde nos seres humanos por ingestão da água, ou de alimentos, peixes e plantas. Quanto ao uso do ferro e da pólvora ocorre o desdobramento destas atividades com uma ampliação da devastação da cobertura vegetal e, do processo de assoreamento se intensificar em relação ao solo. 
A análise também poderia incorporar a condição de escravidão do trabalho indígena, do ponto de vista de sua brutalidade e da expropriação de suas terras, sendo que as mesmas encontram-se incorporadas de valores culturais simbólicos que são distintos dos valores dos autodenominados civilizados. Consideramos que estas possibilidades de análise se inserem no campo da história ambiental, por reconhecermos o entrelaçamento homem-natureza se efetivando sob a forma da produção de sua vida material e cultural.

Vejamos, uma outra passagem dos mesmos autores, comentando a produção açucareira no Brasil colonial:

Um bom engenho devia contar, no mínimo, com cinqüenta escravos, bois e cavalos, além de muita lenha. A exuberante Mata Atlântica nordestina foi toda devastada nos séculos de produção açucareira, para ser capaz de abastecer os engenhos de lenha. (MARANHÃO e ANTUNES, 199, p. 209)

Temos a condição neste momento de estabelecer os seguintes comentários: o complexo funcionamento do fluxo ecossistêmico da Mata Atlântica, rica em biodiversidade e que a auto-sustenta há milênios é simplificado e empobrecido. Isto ocorre devido a utilização deste ecossistema por uma determinada sociedade, em uma determinada época, realizando segundo seus valores culturais, conhecimento e técnica, uma exploração que define a intensidade da extração econômica e ornamental dos elementos naturais. A degradação também se realiza pelo estilo de prática agrícola, no caso, monocultura de cana e, pela entrada de espécies exógenas no sistema ecológico podendo vir a degradá-lo.

Este exemplo, se circunscreveu a sociedade colonial brasileira, mas esta perspectiva de análise em História Ambiental, poderia também se realizar analisando outras sociedades em épocas distintas..

Estes autores, anteriormente referidos, também realizam o seguinte comentário sobre os povos nativos no Brasil:

Os tupis-guaranis [...] Cada um desses povos possuía várias aldeias, próximas a algum rio onde se vivia da caça, da pesca, da coleta e de uma agricultura seminômade. Eles ocupavam uma área e lá plantavam durante alguns anos, até a terra ficar esgotada, ou seja, tornar-se quase improdutiva. Isso acontecia porque 
eles não adubavam a terra. Quando acaba a fertilidade do solo, eles desmatavam outro trecho, faziam a queimada e iniciavam novas roças.(MARANHÃo e ANTUNES, 1999, p. 113)

Notamos nestes parágrafos uma simplificação da complexa atividade realizada pelos nativos, não havendo uma descrição e análise das artes, conhecimento e técnicas de convivência com o meio ambiente. Expressando ainda uma consideração de que a prática agrícola adotada pelos nativos, levava a exaustão da fertilidade do solo pela ausência de adubação e prática de queimada.

Não é raro localizarmos em nossos meios de comunicação, notícias alarmantes em pleno século XXI, de uma intensa prática de queimada realizada por modernas empresas agropecuárias, ou de esgotamento de solo por sua utilização inadequada.

Percebam, por exemplo, como a prática indígena de queimada é vista através de uma outra perspectiva no livro, História Temática: Diversidade Cultural e Conflitos.

[grupos indígenas] Essa característica faz com que os grupos não se fixem num único lugar, buscando sempre melhor região de caça, maior riqueza de coleta e terrenos mais férteis. Por se tratar de pequenos grupos, seu modo de vida pouco agride a natureza. Mesmo abrindo clareiras em florestas e explorando-as, esses indígenas não esgotam a possibilidade de recuperação natural do meio. (PILLETI e PILLETI, 2000, p. 75)

Reconhece-se, assim, que a estratégia utilizada pelos indígenas não esgota a capacidade de recuperação do meio ambiente estamos, portanto, visualizando atividades de distintas sociedades em relação ao seu meio-ambiente. Tais possibilidades de ponderação sobre o tema podem se efetivar de uma forma mais apropriada quando buscamos compreender melhor os processos de funcionamento do fluxo ecossistêmico e, também, por intermédio da análise histórica da produção, reprodução e representação da vida material e cultural.

Os autores Claudino e Nelson Pilleti, utilizam-se dos estudos de um antropólogo para explicitarem o processo cultural destes povos em convivência com o meio ambiente: 
Classificação de plantas e animais entre os indígenas.

Claude Lévi-Strauss, importante antropólogo francês nascido em 1908, realizou pesquisas, na década de 1930, em diferentes comunidades indígenas do Brasil. Ficou impressionado com a riqueza da cultura desses povos. É dele o texto que vamos ler: Os indígenas têm um sentido agudo das árvores características dos arbustos e das ervas próprias de cada "associação vegetal", tomando esta expressão no sentido ecológico. São capazes de enumerar, nos maiores detalhes e sem qualquer hesitação, as árvores próprias de cada associação, o gênero da fibra e da resina, as ervas, as matérias primas que fornecem, assim como os mamíferos e as aves que freqüentam cada tipo de hábitat (PILLETI e PILLETI, 2003, p. 86).

Condizente com esta linha de análise, reconhece-se um profundo conhecimento milenar dos povos indígenas sobre o seu mundo entendendo que sociedade humana e ambiente fazem parte de um único sistema. Como decorrente deste conhecimento nativo poderíamos, também, apresentar uma problematização que diz respeito aos problemas da biopirataria realizada por grandes corporações transnacionais da área médica, que estão se apropriando indevidamente, isto é, roubando sob a forma de direito de patentes, o conhecimento indígena sobre a natureza e, até de seu DNA depositado em bancos genéticos para futuros empreendimentos de engenharia.

Piletti destaca em seu livro um tópico sobre a questão ecológica:

A questão ecológica

A preocupação em promover a exploração adequada dos recursos naturais do planeta, com o reparo dos danos já causados à natureza, com a preservação do meio ambiente e com o combate à poluição, está presente em todos os níveis da sociedade. Mas é sobretudo na escola que esta preocupação mais se faz necessária. A preservação do meio ambiente é hoje também objeto de medidas por parte do governo da maioria dos países. Além disso, as conferências mundiais são organizadas com o objetivo de definir políticas de alcance mundial na área ambiental. Uma das mais importantes conferências foi a Rio-92, na qual representantes de 150 países assinaram duas importantes resoluções: a primeira, destinada a tomar medidas para evitar o aquecimento do globo; a segunda, destinada a preservar espécies animais e vegetais. Nos seus livros de ciências, reveja 0 assunto do meio ambiente (PILLETI e PILLETI, 2003, p. 217). 
0 reconhecimento da importância de se discutir este assunto na escola é ressaltado, bem como, da preocupação com a preservação do meio ambiente. Apesar de ser esta obra, entre as três escolhidas, a única que apresenta uma amplitude maior em relação a questão ecológica através deste tópico específico, podemos notar que 0 assunto sobre o meio ambiente é remetido aos livros de ciências, sendo perdida a possibilidade de estudá-lo por intermédio de uma análise em história ambiental do processo de produção industrial considerado como um dos principais fatores dos problemas ecológicos.

Nossa contribuição ao professor de história que se utiliza deste livro e/ou assunto aponta para um estudo que busque compreender historicamente como se constituiu uma visão mecânica, sobre um mundo que é também orgânico, como anteriormente nos fundamentamos. Este horizonte encontra-se atravessado por saborosos desafios, vamos desfrutá-los?

\section{Referências}

ARAS, L. M. B. A implantação da LDB/96 e os cursos de história. In: SCHMIDT, M. A.; CAINELLI, M. R. (orgs.) III Encontro: Perspectivas do Ensino de História, Curitiba: Aos Quatro Ventos, 1999, p.381-392.

ARAÚJO, F. M. L. A(s) História(s) produzida(s) nos livros didáticos. In: SCHMIDT, M. A.; CAINELLI, M. R. (orgs.) III Encontro: Perspectivas do Ensino de História, Curitiba: Aos Quatro Ventos, 1999, p.237-251.

ARAÚJ0, U. F. Apresentação à edição brasileira. In: BUSQUETS, M.D. Temas transversais em educação: bases para uma formação integral, São Paulo: Ática, 1999.

AVANCINI, E. Ensino de História no Brasil: Perspectivas e Tendências. ÁGORA, Santa Cruz do Sul, V.4, n 12/2, p23-39, jan/dez, 1998, p.23-39.

BRASIL. Secretaria da Educação Fundamental. Parâmetros Curriculares Nacionais: terceiro e quarto ciclos: apresentação dos Temas Transversais. Brasília: MEC/SEF, 1998.

CAIMI, F. E. e outros (orgs.) O livro didático e o currículo de bistória em transição, Passo Fundo - RS: UFP, 2002.

Câmara Brasileira do Livro. Comportamento do Setor Editorial Brasileiro, 1996.

CAPRA, E. O ponto de mutação. Trad. Álvaro Cabral, São Paulo: Cultrix, 1987. 
CHAUÍ, M. Ideologia e Educação, Educação e Sociedade. Cortez/Autores Associados, ano II, n. 5, Janeiro, 1980.

BITTENCOURT, C. Livros didáticos entre textos e imagens. BITTENCOURT, C. (Org.) O saber Histórico na sala de aula, São Paulo: Contexto, 1997.

. Meio Ambiente e Ensino de História, História e Ensino, Revista do Laboratório de Ensino de História, Londrina: EDUEL, 2003. v.9, p.37-61.

GAVIDIA, V. A construção do conceito de transversalidade. ÁLVAREZ, M. N. e outros. Valores e temas transversais no currículo. Porto Alegre: Artmed, 2002, p.15-30.

ILLICH, I. Sociedade sem escolas. Trad. Lúcia M. E. Orth. Petrópolis: Vozes, 1982.

MARANHÃO, R.; ANTUNES, M. F. Trabalho e Civilização: Uma História Global. São Paulo: Moderna, 1999.

MARTINEZ, R. Geografia e Meio Ambiente: Uma análise do pensamento geográfico e da problemática ambiental nos parâmetros curriculares nacionais. Marília-SP. Dissertação de Mestrado, Programa de Pós-graduação em Educação, Unesp, 2003.

MICELI, P. História, Histórias: O jogo dos jogos. Campinas: Unicamp, 1996.

MONTELLATO, A. R. D. e outros. História Temática: Diversidade Cultural e Conflitos. São Paulo: Scipione, 2000.

MORIN, E. O método. Trad. Maria G. de Bragança, Lisboa: Europa-América, 1987, volumes I, II, III e IV.

MUNAKATA, K. Histórias que os livros didáticos contam, depois que acabou a ditadura no Brasil. FREITAS, M. C. (Org.) Historiografia Brasileira em Perspectiva. São Paulo: Contexto, 1998.

NEVES, J. Perspectivas do Ensino de História: desafios político educacionais e historiográficos. SCHMIDT, M. A.; CAINELLI, M. R. (orgs.) III Encontro: Perspectivas do Ensino de História. Curitiba: Aos Quatro Ventos, 1999, p.708-732.

PAES DE ALMEIDA, J. A extinção do Arco-íris: Ecologia e História. Campinas: Papirus, 1988.

1996.

Errante no campo da Razão: O inédito na História, Londrina: Ed.UEL, 
PILETTI, C.; PILETTI, N. História e Vida Integrada. São Paulo: Ática, 2003,

PURIFICAÇÃO, A. T. de S. e C. (Re)criando interpretações sobre a independência do Brasil: Um estudo das mediações entre memória e bistória nos livros didáticos. São Paulo: USP, 2002.

REVISTA Nova História, ano XI, N.77, São Paulo: Abr/Ago, 1994.

SÁ MOTTA, M. H. Um Estudo sobre causalidade no ensino de História. Belo Horizonte: Faculdade de Educação da UFMG, 2002, Dissertação de Mestrado.

SOFFIATI, A. A ausência da natureza nos livros didáticos de história. NADAI, E. (org.) Anais do Seminário "Perspectivas do Ensino de História". Faculdade de Educação: USP: São Paulo, 1988, p.533-545.

TIEZZI, E. Tempos históricos, tempos biológicos. Trad.Frank R. C. Ferreira e Luiz E. de L. Brandão. São Paulo, Nobel, 1988.

ZAMBONI, E. A visão dos "Descobrimentos" na literatura didática. Educação na América Latina, (Coord. Circe M. Bittencourt e Zilda M. G. Iokoi), São Paulo: Edusp, 1996.

\section{Transverse Horizon: The spread scientific knowledge about environmental in the history didactics books}

\section{ABSTRACT}

This article is a study in the field of environmental history and teaching history and, your purpose was looking to knowledge how the transverse theme environmental was to approach in the history didactics books.

Key-words: teaching history, environmental history, science history. 